thẳng tuyến tính thuận chiều. Biểu đồ đám mây của chỉ số Sokolow Lyon phân tán rộng nhất, cho giá trị hệ số tương quan thấp nhất( $R=0,17)$, còn biểu đồ đám mây của chỉ số Cornell thì tập trung quanh đường hồi quy, nên giá trị hể số tương quan cao hơn $(R=0.19)$ có ý nghĩa thống kê.

Độ nhay, độ đặc hiệu của 4 tiêu chí ĐTÐ: Chúng tôi thấy độ nhạy của 4 chỉ số ĐTĐ không khác nhau nhiêu và đều ở mức thấp, nhưng độ đặc hiệu của cả 4 tiêu chí ĐTĐ lại rất cao. Nhưng khi so sánh giá trị các chỉ số ĐTĐ ở cùng độ đặc hiệu: mặc dù độ nhạy của 4 chỉ số ĐTĐ là thấp nhưng khi so sánh chúng với nhau ở cùng độ đặc hiệu $90 \%, 95 \%$, và $100 \%$ thì chỉ số Cor V lại cho kểt quả cao hơn các chỉ số còn lại nhưng không có ý nghĩa thống kê.

So sánh đồ thị đường cong ROC của các chỉ số ĐTĐ: Chúng tôi thấy đường cong của chỉ số Cor $V$ nằm cao nhất ở cả 2 giới $(0,617$ ở nam; 0,525 ở nữ), đường cong của chỉ số Sok $V$ là thấp nhất, đặc biệt là ở giới nữ, mặc dù diện tích dưới đường cong của 4 tiêu chí ĐTÐ có khác nhau nhưng chưa có ý nghĩa thống kê và mức độ tương quan của từng chỉ số khi test chẩn đoán PĐTT lại ở mức yếu. Sau khi viết phương trình hồi quy cho các yếu tố ảnh hưởng đến chẩn đoán PĐTT chúng tôi thấy rằng: thời gian THA, chỉ số khối cơ thể (BMI), và có rối loạn lipid máu ảnh hưởng tới các chỉ số ĐTĐ, cụ thể là khi các yếu tố này tăng lên thì mức độ PĐTT cũng sẽ tăng lên.

\section{KẾT LUÂN}

Chỉ số điện thế Cornell có giá trị chẩn đoán PĐTT tương đương chỉ số Sokolow Lyon.

TÀI LIỆU THAM KHẢO
1. Sundström, J. et al. Echocardiographic and electrocardiographic diagnoses of left ventricular hypertrophy predict mortality independently of each other in a population of elderly men. Circulation 103, 2346-2351 (2001).

2. Molloy, T. J., Okin, P. M., Devereux, R. B. \& Kligfield, P. Electrocardiographic detection of left ventricular hypertrophy by the simple QRS voltageduration product. J. Am. Coll. Cardiol.20, 11801186 (1992).

3. Electrocardiographic detection of left ventricular hypertrophy using echocardiographic determination of left ventricular mass as the reference standard. Comparison of standard criteria, computer diagnosis and physician interpretation - PubMed. https:// pubmed.ncbi.nlm.nih.gov/6228571/.

4. Huỳnh Văn Minh, Phạm Gia Khải, Đặng Vặn Phước, Nguyến Lân Viête. Khuyến cáo về chẩn đoán và điêu trị THA 2018. Hội Tim mach hoc Viêt nam

5. Su, F.-Y. et al. A comparison of Cornell and Sokolow-Lyon electrocardiographic criteria for left ventricular hypertrophy in a military male population in Taiwan: the Cardiorespiratory fitness and HospItalization Events in armed Forces study. Cardiovasc. Diagn. Ther.7, 244-251 (2017).

6. Jj, N., Ta, A., Uf, N., C, N. \& Am, J. A metaanalytic evaluation of the diagnostic accuracy of the electrocardiographic Peguero-Lo Presti criterion for left ventricular hypertrophy. J. Clin. Hypertens. Greenwich Conn22, (2020).

7. Performance of Electrocardiographic Criteria for Echocardiographically Diagnosed Left Ventricular Hypertrophy in Chinese Hypertensive Patients - PubMed. https:// pubmed.ncbi.nlm.nih.gov/ 32484222/.

8. Sokolow, M. \& Lyon, T. P. The ventricular complex in left ventricular hypertrophy as obtained by unipolar precordial and limb leads. Am. Heart J.37, 161-186 (1949).

9. Giá trị của chỉ số norman trong chẩn đoán phì đại thất trái. https:// 123docz.net/ document/5950328-gia-tri-cua-chi-so-normantrong-chan-doan-phi-dai-that-trai.htm.

\title{
KẾT QUẢ ĐIỀU TRI HộI CHỨNG CHÈN ÉP KHOANG DƯỚI MỎM CÙNG VAI BẰNG TIÊM CORTICOSTEROID DƯớI HƯỚNG DẪN SIÊU ÂM
}

\author{
Hà Thanh Tâm ${ }^{1,2}$, Nguyễn Thị Ngọc Lan ${ }^{1}$, Phạm Hoài Thu ${ }^{1}$
}

\section{TÓM TẮT}

Muc tiêu nghiên cứu: Đánh giá kết quả điều trị hội chứng chèn khoang dưới mỏm cùng vai bằng tiêm

\footnotetext{
${ }^{1}$ Trường Đại học Y Hà Nội

²Bênh viện Trung ương Thái Nguyên

Chịu trách nhiệm chính: Phạm Hoài Thu

Email: phamhoaithu@hmu.edu.vn

Ngày nhận bài: 5.8.2021

Ngày phản biên khoa hoc: 4.10 .2021

Ngày duyệt bài: 15.10 .2021
}

corticosteroid dưới hướng dẫn của siêu âm và nhân xét một số tác dụng không mong muốn của liệu pháp.Đối tượng và phương pháp nghiên cứu: Nghiên cứu can thiêp theo dõi doc 29 bênh nhân với 34 khớp vai tổn thương, được chẩn đoán hội chứng chèn ép khoang dưới mỏm cùng vai và được tiêm 1 mũi Methylprednisolon acetat $40 \mathrm{mg}$ (Depomedrol 40 $\mathrm{mg}$ ) vào bao thanh dịch dưới mỏm cùng vai dướ hướng dẫn của siêu âm. Kết quả nghiên cứu: Sau 4 tuần điều trị có sự cải thiên về thang điểm VAS, EFA và góc dạng khớp vai. Đánh giá tại thời điểm trước tiêm và sau tiêm 4 tuần, VAS trung bình giảm từ 6,67 
\pm 0,84 điểm xuống 2,08 $\pm 1,31$ điểm. Điểm EFA và góc dạng khớp vai trung bình tăng tương ứng từ 9.73 \pm 1.54 điểm lên $15,30 \pm 1,64$ điểm và từ $63,08 \pm$ 14,30 độ lên 116,32 $\pm 16,84$ độ. Có sự khác biệt trước và sau điêu trịvới $p<0,05$. Tác dụng không mong muốn gặp trong quá trình điều trị là đau tăng tại vị trí tiêm. Có 12 khớp vai trong tổng số 34 khớp vai chiếm $35,29 \%$ đau tăng tại vị trí tiêm sau 24h. Không ghi nhận trường hợp nào có biểu hiện đau đầu, chóng mặt, sốc, nóng bừng mặt và nhiếm trùng tại chố sau tiêm. Kết luận: Điều trị hội chứng chèn ép khoang dưới mỏm cùng vai bằng phương pháp tiêm corticosteroid dưới hướng dẫn của siêu âm đạt kết quả tốt và là một liệu pháp an toàn, ít gặp các tác dụng không mong muốn.

Tư khóa: Hội chứng chèn ép khoang dưới mỏm cùng vai, tiêm corticosteroid, tiêm dưới hướng dẫn siêu âm

\section{SUMMARY \\ RESULTS OF TREATMENT OF SUBACROMIAL IMPINGEMENT SYNDROME WITH CORTICOSTEROID INJECTION UNDER ULTRASOUND GUIDANCE}

Objectives: To evaluate the results of treatment of subacromial impingement syndrome with corticosteroid injection under ultrasound guidance and to comment on some undesirable effects of the therapy. Methods: Interventional study longitudinal follow-up 29 patients with 34 injured shoulder joints, diagnosed with subacromial impingement syndrome and received 1 injection of Methylprednisolone acetate $40 \mathrm{mg}$ (Depomedrol 40mg) into the subacromial bursa under ultrasound guidance. Results: After 4 weeks of treatment, there was an improvement in VAS, EFA and shoulder angle. Assessed at the time of injection and 4 weeks after injection, the average VAS decreased from $6.67 \pm 0.84$ points to $2.08 \pm 1.31$ points. The mean EFA score and shoulder angle angle increased respectively from $9.73 \pm 1.54$ points to $15.30 \pm 1.64$ points and from $63.08 \pm 14.30$ degrees to $116.32 \pm$ 16.84 degrees. The difference before and after treatment was statistically significant with $p<0.05$. An undesirable effect encountered during treatment is increased pain at the injection site. There were 12 shoulder joints out of 34 shoulder joints, accounting for $35.29 \%$ of the increased pain at the injection site after 24 hours. There were no cases of headache, dizziness, shock, hot flushes and local infection after injection. Conclusions: Treatment of subacromial impingement syndrome by corticosteroid injection under ultrasound guidance achieved good results and was a safe therapy, with few undesirable effects.

Keywords; subacromial impingement syndrome, corticosteroid injection, ultrasound guided injection.

\section{I. ĐĂT VẤN ĐỀ}

Hội chứng chèn ép khoang dưới mỏm cùng vai (Subacromial impingement syndrome) là tình trạng cọ sát về mặt cơ học giữa các tổ chức phần mềm là gân chóp xoay, túi hoạt dịch dưới mỏm cùng vai với mấu động lớn xương cánh tay và mặt dưới của mỏm cùng vai và dây chằng cùng quạ ${ }^{1}$ Tình trạng diễn biếnkéo dài dẫn đến biên chứng đứt gẩn, rách chóp xoay. Biểu hiện bởi đau và hạn chế tầm vận động khớp vai, ảnh hưởng nhiều đến sinh hoạt và chất lượng cuộc sống của người bệnh. Điều trị hội chứng chèn ép khoang dưới mỏm cùng vai hiện nay thường là các thuốc NSAIDs đơn thuần hoăc kết hợp với vật lý trị liệu, xong thường tái phát. Việc đưa thuốc vào đúng vị trí bao thanh dịch dưới mỏm cùng vai dưới hướng dẫn siêu âm giúp làm tăng hiệu quả điều trị một cách rõ rệt ${ }^{2}$. Hiện nay, tại Việt Nam chưa có nghiên cứu nào về vấn đề này. Vì vậy chúng tôi tiến hành nghiên cứu đề tài này với 2 mục tiêu:

1. Đánh giá kêt quả điều trị hội chứng chèn ép khoang dưới mỏm cùng vai bằng tiêm corticosteroid dưới hướng dẫn của siêu âm

2. Nhận xét một số tác dụng không mong muốn của liệu pháp.

\section{II. ĐỐl TƯỢNG VÀ PHƯƠNG PHÁP NGHIÊN CỨU}

2.1. Đối tượng nghiên cứu: Gồm 29 bệnh nhân với 34 khớp vai tổn thương đến khám tại phòng khám Cơ xương khớp bệnh viện Bạch Mai từ tháng 1/2021 đến tháng 7/2021 được chẩn đoán hội chứng chèn ép khoang dưới mỏm cùng vaitheo tiêu chuẩn chẩn đoán Neer (1972) ${ }^{3}$ gồm các triệu chứng: Đau khớp vai $\geq 1$ tháng, VAS $\geq$ 4,có hạn chế vận động khớp vai, nghiệm pháp Neer và/hoặc Hawkins dương tính. Siêu âm khớp vai có viêm bao thanh dịch dưới mỏm cùng vai có thể kèm theo viêm gân chóp xoay, điển hình là viêm gân trên gai. Khoảng cách từ mỏm cùng vai đến chỏm xương cánh tay $\leq 6 \mathrm{~mm}$ được xác định trên Xquang chữ $Y$ (Outlet view)

Loại khỏi nghiên cứu các trường hợp có hội chứng nhiễm trùng toàn thân trên lầm sàng, bệnh nhân có các chống chỉ định của corticosteroid (tổn thương da tại vị trí tiêm, đái tháo đường, tăng huyết áp không được kiểm soát, dị ứng với corticoid...). Bệnh nhân đã tiêm corticosteroid tại khớp vai trong vòng 3 tháng.

2.2. Phương pháp nghiên cứu: Nghiên cứu tiến cứu, theo dõi dọc, có can thiệp. Cách chọn mẫu thuận tiện. Bệnh nhân được chẩn đoán có hội chứng chèn ép khoang dưới mỏm cùng vai được tiêm 1 mũi Methylprednisolone (Depomedrol $40 \mathrm{mg}$ ) vào bao thanh dịch dưới mỏm cùng vai dưới hướng dẫn siêu âm. Thủ thuật được tiến hành bởibác sỹ chuyên khoa Cơ xương khớp. Sử dụng máy siêu âm Medison Accuvix v 10.0, đầu dò Linear tần số 5-13 Mhz tại phòng khám Cơ xương khớp, BvBạch Mai. 
Đánh giá kết quả điều trị dựa trên thang điểm đau VAS, thang điểm EFA đánh giá mức độ hoạt đônng khớp và góc dạng khớp vai tại các thời điểm trước điều trị (TO), sau điều trị 1 tuần (T1), và sau điều trị 1 tháng (T4). Theo dõi tác dụng không mong muốn của liệu pháp được ghi nhận sau tiêm 30 phút, sau tiểm 1 ngày và tại các thời điểm đánh giá.

2.4. Sử lý số liệu theo phân mềm thống kê: SPSS 20.0

III. KẾT QUẢ NGHIÊN CỨU

3.1. Đặc điểm chungcủa bệnh nhân nghiên cứu

Bảng 1: Đặc điểm bệnh nhân nghiên cứu (n= 29 bệnh nhân)

\begin{tabular}{|c|c|c|c|c|}
\hline \multicolumn{3}{|c|}{$\begin{array}{c}\text { Đặc điểm bệnh nhân nghiên } \\
\text { cứu }\end{array}$} & \multicolumn{2}{|c|}{\begin{tabular}{c|c}
\multicolumn{2}{c}{$n=29$} \\
Số lượng \\
$\begin{array}{c}\text { Tỷ lệ } \\
\text { (n) }\end{array}$
\end{tabular}} \\
\hline \multirow{2}{*}{ Giới } & & Nam & 10 & 34,5 \\
\hline & & Nũ̃ & 19 & 65,5 \\
\hline \multicolumn{3}{|c|}{ Tuổi trung bình ( $34-70$ tuổi) } & \multicolumn{2}{|c|}{$56,76 \pm 8,50$} \\
\hline \multirow{4}{*}{$\begin{array}{l}\text { Nghề } \\
\text { nghiệp }\end{array}$} & \multirow{3}{*}{\multicolumn{2}{|c|}{\begin{tabular}{|c|} 
Giáo viên \\
Cán bộ, văn phòng \\
Nông dân, công \\
nhân lao đông năng \\
\end{tabular}}} & 3 & 10,3 \\
\hline & & & 6 & 20,7 \\
\hline & & & 16 & 55,2 \\
\hline & \multicolumn{2}{|c|}{ Nội trợ, bán hang } & 4 & 13,8 \\
\hline \multirow{5}{*}{$\begin{array}{l}\text { Hoạt động } \\
\text { thể lực, } \\
\text { thể dục } \\
\text { thể thao }\end{array}$} & \multirow{5}{*}{ Có } & Bơi lội & 2 & 6,9 \\
\hline & & Yoga & 5 & 17,3 \\
\hline & & $\begin{array}{l}\text { Bóng chuyền, } \\
\text { câuu lông }\end{array}$ & 3 & 10,3 \\
\hline & & Tống & 10 & 45,5 \\
\hline & & Không & 19 & 65,5 \\
\hline \multirow{3}{*}{$\begin{array}{l}\text { Thời gian } \\
\text { mắc bệnh }\end{array}$} & & Dưới 1 tháng & 5 & 17,2 \\
\hline & & $1-3$ tháng & 10 & 34,5 \\
\hline & & Trên 3 tháng & 14 & 48,3 \\
\hline \multirow{3}{*}{$\begin{array}{c}\text { Hoàn cảnh } \\
\text { xuất hiện }\end{array}$} & & Tự nhiên & 19 & 65,5 \\
\hline & Sau & mang vác nặng & 8 & 27,6 \\
\hline & & Chấn thương & 2 & 6,9 \\
\hline
\end{tabular}

Nhân xét: Đa số bênh nhân nghiên cứu là nữ giới $(65,5 \%)$ với tuổi trung bình là $56,76 \pm$
8,50. Nghề nghiệp nông dân, công nhân, người lao động nặng chiếm phần lớn với tỷ lệ $55,2 \%$. Có $10(45,5 \%)$ trường hợp có hoat động thể lực, thể dục thể thao kèm theo. Tỷ lệ bệnh nhân có thời gian mắc bệnh trên 3 tháng cao nhất chiếm 48,3\%. Hoàn cảnh xuất hiện chủ yếu là tự nhiên chiếm $65,5 \%$.

Bảng 2: Vị trí tổn thương ( $n=29$ bênh nhân) \begin{tabular}{|c|c|c|}
\hline Vị trí tổn thương & Số lượng (n) & Tỷ lê \% \\
\hline
\end{tabular}

\begin{tabular}{|c|c|c|}
\hline Vai trái & 9 & $31,0 \%$ \\
\hline Vai phải & 15 & $51,7 \%$ \\
\hline Hai vai & 5 & $17,2 \%$ \\
\hline
\end{tabular}

Nhân xét: 29 bênh nhân với 34 khớp vai bi tổn thương. Trong đó, tổn thương vai phải chiếm $51,7 \%$, vai trái $31,0 \%$ và $17,2 \%$ tổn thương cả 2 vai.

3.2. Đánh giá kết quả điêu trị hội chứng chèn ép khoang dưới mỏm cùng vai bằng phương pháp tiêm corticoid dưới hướng dẫn của siêu âm

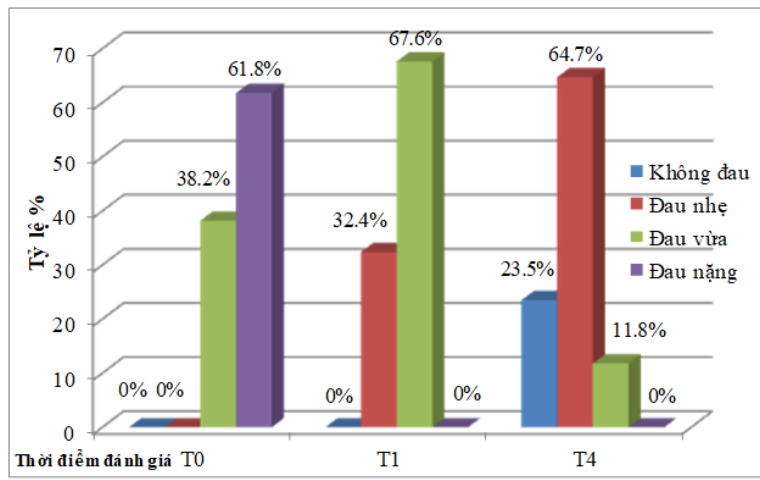

Biểu đồ 1: Kêt quả điều tri qua thang điểm VAS ( $n=34$ khớp vai)

Nhận xét: $100 \%$ bệnh nhân tại thời điểm T0 trước điều trị đều có mức độ đau theo thang điểm VAS ở mức đau vừa và nặng. Mức độ đau được cải thiện ngay sau 1 tuần điều trị và giảm dần ở tuần thứ 4 , tại thời điểm sau điều trị 1 tuần đã không còn bệnh nhân nào đau nặng, có 8 khớp vai $(23,5 \%)$ hoàn toàn hết đau sau 4 tuần điều trị.

Bảng 3: Kết quả điều trị theo thang điểm VAS, EFA và góc dạng khớp vai ( $n=34$ khớp vai)

\begin{tabular}{|c|c|c|c|c|}
\hline & T0 & T1 & T4 & T4-T0 \\
\hline VAS & $6,67 \pm 0,84$ & $4,32 \pm 1,25$ & $2,08 \pm 1,31$ & $-4,58 \pm 1,10$ \\
\hline EFA & $9,73 \pm 1,54$ & $12,62 \pm 1,23$ & $15,30 \pm 1,64$ & $5,55 \pm 2,07$ \\
\hline Góc dạng khớp vai & $63,08 \pm 14,30$ & $84,55 \pm 12,69$ & $116,32 \pm 16,84$ & $53,23 \pm 21,49$ \\
\hline \multicolumn{4}{|r|}{$\mathrm{p}<0,05$} \\
\hline
\end{tabular}

Nhận xét: Có sự cải thiện thang điểm VAS, EFA và góc vận dạng khớp vai sau 1 tuần điều trị và được duy trì đến thời điểm sau 4 tuần. Sự cải thiện có ý nghĩa thống kê $p<0,05$

\subsection{Tác dụng không mong muốn của liệu pháp}

3.3.1. Tại thời điểm làm thủ thuật 
Bảng 4: Chi số mạch, huyết áp trước và sau tiêm ( $n=29$ bệnh nhân)

\begin{tabular}{|c|c|c|c|c|c|c|}
\hline $\begin{array}{c}\text { Chỉ số } \\
\text { theo } \\
\text { dõi }\end{array}$ & $\begin{array}{c}\text { Mạch trước } \\
\text { tiêm }\end{array}$ & $\begin{array}{c}\text { Mạch sau } \\
\text { tiêm }\end{array}$ & $\begin{array}{c}\text { Huyết áp } \\
\text { Tr trước } \\
\text { tiêm }\end{array}$ & $\begin{array}{c}\text { Huyết áp } \\
\text { Tr sau } \\
\text { tiêm }\end{array}$ & $\begin{array}{c}\text { Huyết áp } \\
\text { Trr trước } \\
\text { tiêm }\end{array}$ & $\begin{array}{c}\text { Huyết áp } \\
\text { Trr sau } \\
\text { tiêm }\end{array}$ \\
\hline$X \pm S D$ & $77,58 \pm 5,56$ & $80,03 \pm 4,44$ & $117,37 \pm 9,05$ & $123,00 \pm 9,80$ & $74,24 \pm 6,59$ & $76,82 \pm 9,18$ \\
\hline$p$ & \multicolumn{2}{|c|}{$p<0,05$} & \multicolumn{2}{|c|}{$p<0,05$} & $p>0,05$ \\
\hline
\end{tabular}

Nhân xét: Tại thời điếm trước và sau tiêm 30 phút có sự thay đối về mạch và huyết áp tâm thu $(\mathrm{p}<0,05)$

Bảng 5: Tác dụng không mong muốn tại thời điểm làm thủ thuật ( $n=29$ bệnh nhân)

\begin{tabular}{|c|c|c|}
\hline $\begin{array}{c}\text { Tác dụng khống } \\
\text { mong muốn }\end{array}$ & $\begin{array}{c}\text { Số lượng } \\
\text { (n) }\end{array}$ & $\begin{array}{c}\text { Tỷ lệ } \\
(\mathbf{\%})\end{array}$ \\
\hline $\begin{array}{c}\text { Sốc phản vệ } \\
\text { Nóng bừng, đaù đầu, } \\
\text { chóng mặt }\end{array}$ & 0 & 0 \\
\hline Cường phể vị & 0 & 0 \\
\hline Chảy máu tại chồ & 0 & 0 \\
\hline
\end{tabular}

Nhận xét: Tại thời điểm làm thủ thuật không có bệnh nhân nào có biểu hiện toàn thân như sốc, nóng bừng, đau đâu, chóng mặt, cũng không có bệnh nhân nào bị chảy máu tại chố tiêm.

3.3.2. Tại thời điểm sau tiêm 1 ngày đến 4 tuần

Bảng 6: Tác dụng không mong muốn của liệu pháp

tại thời điểm sau tiêm 1 ngày đến 4 tuần $(n=34$ khớp vai)

\begin{tabular}{|c|c|c|c|}
\hline Vị trí & $\begin{array}{c}\text { Tác dụng } \\
\text { không mong muốn }\end{array}$ & $\begin{array}{c}\text { Số lượng } \\
\text { (n) }\end{array}$ & $\begin{array}{c}\text { Tỷ lệ } \\
(\mathbf{\%})\end{array}$ \\
\hline \multirow{4}{*}{ Tại chỗ } & $\begin{array}{c}\text { Đau tăng tại vị trí } \\
\text { tiêm }\end{array}$ & 12 & 35,29 \\
\cline { 2 - 4 } & Nhiêm trùng & 0 & 0 \\
\cline { 2 - 4 } & $\begin{array}{c}\text { Teo da, bạch biến } \\
\text { trên da }\end{array}$ & 0 & 0 \\
\hline
\end{tabular}

Nhận xét: Sau tiêm có 12 khớp vai $(35,29 \%)$ đau tăng sau tiêm 1 ngày. Không có trường hợp nào nhiễm trùng, teo da, bạch biến trên da.

\section{BÀN LUẬN}

4.1. Kết quả nghiên cứu. Hội chứng chèn ép khoang dưới mỏm cùng vai là hội chứng hay gặp trên lâm sàng. Theo nghiên cứu của Dhillon năm 2019, đã chỉ ra rằng hội chứng này chiếm khoảng $48 \%$ các trường hợp đau vai, các biểu hiện đau mạn tính với thời gian bị bệnh $\geq 3$ tháng ${ }^{4}$. Nghiên cứu của chúng tôitại bảng 1 chothấy phần lớn bệnh gặp ở nữ giới, với tỷ lệ $65,5 \%$, độ tuổi trung bình trong nghiên cứu là $56,76 \pm 8,50$. Năm 2020, nghiên cứu củaNajibeh Akbari khi thực hiện tiêm corticoid điêu trị hội chứng chèn ép khoang dưới mỏm cùng vai cho 28 bệnh nhân cũng nhận thấy điều tương tự với tỷ lệ nữ nhiều hơn nam. Cụ thể trong nghiên cứu này nữ chiếm $60,71 \%$ và nam là $39,29 \%$ với độ tuổi trung bình là $42,5^{2}$

Một số yễu tố khởi phát đau ở nhóm bệnh nhân có hội chứng chèn ép khoang dưới mỏm cùng vai như chấn thương, mang vác, xách nặng... Tuy nhiên trong nghiên cứu này chúng tôi chỉ gặp 2 trường hợp $(6,9 \%)$ có chấn thương, 8 trường hợp $(27,6 \%)$ sau mang vác nặng. Còn phần lớn bệnh xuất hiện tự nhiên chiếm $65,5 \%$. Vị trí đau chủ yếu là vai phải có $15(51,7 \%)$ trường hợp, vai trái có $9(31,0 \%)$ trường hợp và $5(17,2 \%)$ trường hợp đau cả 2 vai. Tương tự như nghiên cứu của Dogu và cộng sự (2012) tiến hành nghiên cứu trên nhóm gồm 23 bệnh nhân được chỉ định tiêm corticosteroidid tại chỗ điều trị hội chứng chèn ép khoang dưới mỏm cùng vai, cho thây đa số vai tổn thương là vai phải với 15 trường hợp chiếm $65,2 \%$ và 8 trường hợp chiếm $34,8 \%$ đau vai trái ${ }^{5}$. Trong nghiên cứu của chúng tôi, nhóm bệnh nhân là nông dân, công nhân, người lao động nặng hay mang vác hoặc động tác lao động thường đưa cánh tay cao hởn $90^{\circ}$, thì tỷ lệ mắc bệnh cao hơn với 55,2 \%. Cụ thể trong nhóm nghiên cứu của chúng tôi, bệnh nhân ở nhóm lao động nặng làm các nghề như công nhân, thợ xây, lái xe, cơ khí, khuân vác, làm ruộng... Ngoài ra, trong nghiên cứu của chúng tôi còn ghi nhận các trường hợp có hoạt động thể lực, thể dục thể thao kèm theo như: bơi lội ghi nhận 2 trường hợp $(6,9 \%)$, yoga có 5 trường hợp $(17,3 \%)$, chơi bóng chuyền, cầu lông có 3 trường hợp (10,3\%).

Kết quả nghiên cứu của chúng tôi cho thấy, điều trị hội chứng chèn ép khoang dưới mỏm cùng vai bằng phương pháp tiêm corticosteroid dưới hướng dẫn siêu âm được đánh giá theo thang điểm VAS, EFA và góc dạng khớp vai có sự cải thiện qua các thời điểm đánh giá. Tại bảng 3 , điểm VAS trung bình trước tiêm là $6,67 \pm 0,84$, sau tiêm 4 tuần là $2,08 \pm 1,31$, điểm VAS trung bìnhso sánh tại hai thời điểm trước tiêm và sau tiêm 4 tuần giảm 4,58 $\pm 1,10(p<0,05)$. Theo nghiên cứu của Cole năm 2015 trên nhóm 27 bệnh nhân với 28 khớp vai được chỉ định tiêm 1 $\mathrm{ml}$ Depomedrol $40 \mathrm{mg}$ vào khoang dưới mỏm cùng vai dưới hướng dẩn siêu âm, theo dõi trong 4 tuần cũng nhận thấy sự cải thiện về điểm đau VAS. Cụ thể, trong nghiên cứu của Cole điểm 
VAS trung bình trước tiêm và sau tiêm 4 tuần giảm từ $5,9 \pm 0,5$ xuống $3,3 \pm 0,6$. Sự khác biệt giữa điểm đau VAS trước và sau tiêm 4 tuần của nghiên cứu này có ý nghĩa thống kê với $p<0,01^{6}$.

Điểm EFA trung bình tăng tại các thời điểm đánh giá, trước tiêm là $9.73 \pm 1.54$ điểm, sau tiêm 4 tuần là $12,62 \pm 1,23$ điểm. Góc dạng khớp vai trung bình cũng tăng tại các thời điểm đánh giá, trước tiêm là 63,08 $\pm 14,30$ độ, sau tiêm 4 tuần là $116,41 \pm 16,84$ độ. Mức tăng trung bình của thang điểm EFA, góc dạng khớp vai so sánh tại 2 thời điểm trước tiêm và sau tiêm lần lượt là $5,55 \pm 2,07$ điểm và $53,23 \pm$ 21,49 độ, có ý nghĩa thống kê với $p<0,05$. Sự cải thiện bắt đầu xuất hiện từ ngày thứ 3 đến 1 tuần sau tiêm, và 4 tuần sau điêuu trị có 8 khớp vai, chiếm 23,5\% không còn đau, một số khớp vai đau ít và cảm thấy khó khăn khi thực hiện các vận động chủ động như đưa tay ra sau, dạng cánh tay... Nhóm bệnh nhân cải thiện mức độ đau, mức độ hoạt động khớp ít hơn, phần lớn nằm trong nhóm bệnh nhân cao tuổi với thời gian bị bệnh tính từ lúc xuất hiện triệu chứng đau đển lúc được điều trị là trên 3 tháng.

Điều trị hội chứng chèn ép khoang dưới mỏm cùng vai bằng phương pháp tiêm tại chỗ corticosteroid dưới hướng dẫn siêu âm được nghiên cứu của Dogu (2012) đánh giá cao về hiệu quả giảm đau và tính ổn định lâu dàikhi thuốc được đưa chính xác vào bao thanh dịch dưới mỏm cùng vai ${ }^{5}$. Mặt khác, phương pháp này ít gây ra các tác dụng không mong muốn trên đường tiêu hóa, tim mạch, tiết niệu... như khi sử dụng thuốc chống viêm, giảm đau NSAIDs đường toàn thân. Vì thế, đây là phương pháp điều trị an toàn, hiệu quả, nên được áp dụng trong điều trị các bệnh lý khớp vai cũng như bệnh lý tại một số khớp khác.

4.2. Tác dụng không mong muốn của liêuu phápđiêuu trị hội chứng chèn ép khoang dưới mỏm cùng vai bằng tiêm corticoid dưới hướng dẫn siêu âm. Trong nghiên cứu của chúng tôi có 34 khớp vai đau được chỉ định tiêm $1 \mathrm{ml}$ Depomedrol $40 \mathrm{mg}$ vào bao thanh dịch dưới mỏm cùng vai dưới hướng dẫn siêu âm. Bệnh nhân được chúng tôi theo dõi các tác dụng không mong muốn tại thời điểm làm thủ thuật và sau làm thủ thuất 1 ngày đến 4 tuần. Tai bảng 4, cho thấy chỉ số mạch, huyết áp của bệnh nhân có tăng nhe sau tiêm, nhưng các chỉ số này vẫn trong giới hạn bình thường và bệnh nhân không có các biểu hiện toàn thân như đau đầu, hoa mắt, chóng mặt, cường phế vị hay chảy máu tại chỗ sau tiêm. Tại thời điểm sau tiêm 1 ngày đến 4 tuần, chúng tôi ghi nhận 12 khớp vai (35,29\%) đau tăng sau tiêm 24 giờ. Tuy nhiên đau ở mức độ nhẹ, tự hết đau sau 48h, bệnh nhân không phải dùng thuốc giảm đau. Ngoài ra, qua theo dõi, chúng tôi không ghi nhận khớp vai nào có biểu hiện nhiễm trùng tại chỗ, teo da, bach biến trên datại thời điểm sau tiêm 1 tuần và 4 tuần.Nghiên cứu của một số tác giả cho thây liệu pháp tiêm corticosteroid điều trị hội chứng chèn ép khoang dưới mỏm cùng vai ít gặp tác dụng phụ toàn thân. Nghiên cứu của Esperanza Naredo năm 2004, thực hiện tiêm corticosteroid tại chỗ cho nhóm 20 bệnh nhân bị đau vai, chỉ ghi nhận 1 trường hợp gặp tác dụng không mong muốn nhe sau tiêm? ${ }^{7}$. Ngoài ra, nghiên cứu của một số tác giả đã thông báo vế tác dụng không mong muốn trên gân chóp xoay khi tiểm corticosteroid tại chỗ nhưng mức độ ảnh hưởng không đáng kể, nhất là khi sử dụng Methylprednisolone và tiêm 1 mũi duy nhất ${ }^{8}$.

\section{KẾT LUẬN}

Nghiên cứu mô tả can thiệp đánh giá kết quả điều trị hội chứng chèn ép khoang dưới mỏm cùng vai bằng phương pháp tiêm corticosteroid dưới hướng dẫn của siêu âm, cho thấy phương pháp này đem lại hiệu quả điều trị tốt, có ý nghĩa thống kê, thông qua đánh giá sự cải thiện về thang điểm VAS, EFA và góc vận động cánh tay. Ngoài ra, đây còn là một liệu pháp an toàn, ít gặp tác dụng không mong muốn như dùng chống viêm Nsaid đường toàn thân.

\section{TÀI LIÊU THAM KHẢO}

1. Charalambous CP, Eastwood S. Anterior Acromioplasty for the Chronic Impingement Syndrome in the Shoulder: A Preliminary Report. In: Banaszkiewicz PA, Kader DF, eds. Classic Papers in Orthopaedics. Springer London; 2014:301-303. doi:10.1007/978-1-4471-5451-8_74

2. Akbari N, Ozen S, Şenlikçi HB, Haberal $M$, Çetin $\mathbf{N}$. Ultrasound-guided versus blind subacromial corticosteroid and local anesthetic injection in the treatment of subacromial impingement syndrome: A randomized study of efficacy. Jt Dis Relat Surg. 2020;31(1):115-122. doi:10.5606/ehc.2020.71056

3. Neer CS. Anterior acromioplasty for the chronic impingement syndrome in the shoulder: a preliminary report. J Bone Joint Surg Am. 1972;54(1):41-50.

4. Dhillon K. Subacromial Impingement Syndrome of the Shoulder: A Musculoskeletal Disorder or a Medical Myth? Malays Orthop J. 2019;13(3):1-7. doi:10.5704/MOJ.1911.001

5. Dogu B, Yucel SD, Sag SY, Bankaoglu M, Kuran B. Blind or Ultrasound-Guided Corticosteroid Injections and Short-Term Response in Subacromial Impingement Syndrome: A 
Randomized, Double-Blind, Prospective Study. Am J Phys Med Rehabil. 2012;91(8):658-665. doi:10.1097/PHM.0b013e318255978a

6. Cole BF, Peters KS, Hackett L, Murrell GAC. Ultrasound-Guided Versus Blind Subacromial Corticosteroid Injections for Subacromial Impingement Syndrome: A Randomized, DoubleBlind Clinical Trial. Am J Sports Med. 2016;44(3):702-707.

doi: $10.1177 / 0363546515618653$
7. Naredo E, Cabero F, Beneyto $\mathbf{P}$, et al. A randomized comparative study of short term response to blind injection versus sonographicguided injection of local corticosteroids in patients with painful shoulder.] Rheumatol. 2004;31(2):308-314.

8. Buchbinder $R$, Green $S$, Youd JM. Corticosteroid injections for shoulder pain. Cochrane Database Syst Rev. 2003;(1):CD004016. doi:10.1002/14651858.CD004016

\section{ĐINH DANH NẤM CANDIDA ALBICANS Ở BÊNNH NHI TẠI BỆNH VIỆN TRƯỜNG ĐẠI HỌC Y KHOA VINH NĂM 2021}

\section{TÓM TẮT}

Nấm Candida là nguyên nhân hàng đầu gây nhiễm nấm ở trẻ em nhập viện. Do trẻ nhỏ có một hệ thống miễn dịch chưa hoàn thiện, các triệu chứng của bệnh do nấm có thể nặng hơn và khó kiểm soát. Các tổn thương ảnh hưởng tới đời sống và sức khỏe của trẻ em. Nghiên cứu mô tả cắt ngang có phân tích được thực hiện tại Khoa khám bệnh của Bệnh viện trường Đại học Y khoa Vinh từ 01/2021 đến 04/2021 trên 42 bệnh nhân là trẻ em dưới 15 tuổi nhiễm nấm. Kết quả cho thấy, tỷ lệ nhiễm nấm C.albicans ở trẻ em $(88,1 \%)$. Chủ yểu nhiễm ở miệng. Có sự ảnh hưởng của huyết thanh có chứa kháng sinh, kháng nấm liên quan đến thời gian sinh ống mầm.

Tư khóa: nhiếm nấm Candida albicans, trẻ em, xét nghiệm định danh

\section{SUMMARY}

\section{IDENTIFICATION OF CANDIDA ALBICANS IN CHILDREN VISITING THE OUTPATIENT DEPARTMENT OF VINH MEDICAL UNIVERSITY HOSPITAL IN 2021}

Candidiasis is the most common cause of invasive fungal infections in hospitalized children. The symptoms of a fungal infection may be more severe and difficult to control in children who have an underdeveloped immune system. Fungal injuries have an impact on the lives and health of children. The cross-sectional descriptive research was conducted on 42 individuals under the age of 15 who were infected with a fungal illness in the Outpatient Department of Vinh Medical University Hospital from January to April 2021. The findings revealed that $88.1 \%$ of children with fundal infection had Candida albicans fungal infection, with oral infections being the most prevalent. There is an effect of serum containing

${ }^{1}$ Bệnh viện Hữu nghi đa khoa Nghệ An

${ }^{2}$ Trường Đai hoc Y khoa Vinh

Chịu trách nhiểm chính: Nguyễn Ngọc Hòa

Email: nguyen.ngochoa.47s@kyoto-u.jp

Ngày nhân bài: 2.8 .2021

Ngày phản biên khoa hoc: 28.9.2021

Ngày duyệt bài: 5.10 .2021

\section{Nguyễn Ngọc Hòa ${ }^{1}$, Nguyễn Thị Hồng Điệp ${ }^{2}$}

antiobiotics, antifungal medicine on the timing of germ tube generation.

Keywords: Candida albicans infection, children, identification test

\section{I. ĐĂT VẤN ĐỀ}

Nấm Candida là nguyên nhân hàng đầu gây nhiễm nấm ở trẻ em nhập viện. Tỷ lệ nhiễm nấm Candida cao nhất ở trẻ sơ sinh và trẻ nhỏ dưới 1 tuổi [1]. Candida albicans là một loài nấn men sống hoại sinh ở miệng, đường tiêu hóa, nếp nhăn trên da có độ ẩm cao khi có điều kiện thuận lợi bắt đâu tăng sinh gây bệnh. Đặc biệt trên đối tượng là trẻ em hệ miển dịch yếu, khả năng tự vệ sinh còn hạn chế nên tắng nguy cơ nhiễm nấm $C$. albicans. Nhiễm nấm $C$. albicans phát triển quá mức có thể gây nhiễm trùng trên da, miệng, tai, mũi, họng, máu.

Tại một số nước trên thế giới ghi nhận trẻ em nhiễm Candida, bệnh nhi tại Bệnh viện Nhi Đại học Cairo tỷ lế trẻ nhiếm trùng máu do $C$. albicans chiếm 17,3\% [1]. Tại Bệnh viện Nhi Trung ương tỉ lệ trẻ sơ sinh nhiễm trùng do nấm C. albicans là $67,3 \%$ [2]. Nghệ An là một tỉnh nằm trong vùng khí hậu nhiệt đới gió mùa là điều kiện thuận lợi cho sự phát triển của nấm. Trên thực tế lâm sàng ghi nhận các bệnh nhi nhiễm nấm. Nghiên cứu này nhằm mục tiêu xác định tỷ lệ nhiểm và kết quả xét nghiệm định danh nấm $C$. albican ở bênh nhi khám tại Bểnh viện Trường Đại học Y khoa Vinh năm 2021.

\section{II. ĐỐI TƯỢNG VÀ PHƯƠNG PHÁP NGHIÊN CỨU}

1. Đối tượng nghiên cứu. Bênh nhi nhiễm nấm đến khám tại Bệnh viện Trường ĐHY khoa Vinh từ tháng 1/2021 đến 4/2021 thỏa mãn điều kiện nghiên cứu.

2. Thiết kế nghiên cứu: mô tả cắt ngang có phân tích 